\title{
Erratum to: Two $O$-methyltransferases involved in the biosynthesis of methoxypyrazines: grape-derived aroma compounds important to wine flavour
}

\author{
Jake D. Dunlevy $\cdot$ Kathleen L. Soole $\cdot$ Michael V. Perkins • \\ Eric G. Dennis · Robert A. Keyzers $\cdot$ Curtis M. Kalua $\cdot$ Paul K. Boss
}

Published online: 8 February 2013

(C) Springer Science+Business Media Dordrecht 2013

\section{Erratum to: Plant Mol Biol (2010) 74:77-89 \\ DOI 10.1007/s11103-010-9655-y}

Due to an unfortunate turn of events, an incorrect version of Table 1 has been used in the above mentioned publication. The $k_{\text {cat }}$ and $k_{\text {cat }} / K_{\mathrm{m}}$ values in the original publication were found to be incorrectly calculated, and these have been corrected in the following table. The original values would have implied that the enzyme is inactive against the hydroxypyrazine substrates. The corrected table shows that the VvOMT1 and VvOMT2 enzymes have $k_{\mathrm{cat}}$ values, when hydroxypyrazines are used as substrates, that suggest catalytic production of methoxypyrazines by these enzymes is possible.
Table 1 Kinetic parameters of recombinant VvOMT1 and VvOMT2 using HPs as substrates

\begin{tabular}{llclc}
\hline Enzyme & Substrate & $\begin{array}{c}\text { Apparent } \\
K_{\mathrm{m}}(\mu \mathrm{M})\end{array}$ & $k_{\text {cat }}\left(\mathrm{s}^{-1}\right)$ & $\begin{array}{l}k_{\text {cat }} / K_{\mathrm{m}} \\
\left(\mathrm{M}^{-1} \mathrm{~s}^{-1}\right)\end{array}$ \\
\hline VvOMT1 & IBHP & $539(31)$ & $0.71(0.03)$ & $1,317(62)$ \\
& IPHP & $493(28)$ & $0.36(0.02)$ & $730(31)$ \\
VvOMT2 & IBHP & $628(29)$ & $0.09(0.002)$ & $137(3)$ \\
& IPHP & $1,264(120)$ & $0.19(0.01)$ & $150(10)$
\end{tabular}

Standard error values are given in parentheses
The online version of the original article can be found under doi:10.1007/s11103-010-9655-y.

J. D. Dunlevy · K. L. Soole

School of Biological Science, Flinders University of South

Australia, GPO Box 2100, Adelaide, SA 5001, Australia

M. V. Perkins - E. G. Dennis

School of Chemistry, Physics and Earth Sciences, Flinders

University of South Australia, GPO Box 2100, Adelaide,

SA 5001, Australia

R. A. Keyzers · C. M. Kalua · P. K. Boss ( $₫)$

CSIRO Plant Industry and Food Futures Flagship,

PO Box 350, Glen Osmond, SA 5064, Australia

e-mail: paul.boss@csiro.au 